\title{
ON POINTWISE APPROXIMATION OF FUNCTIONS
}

\section{BY SOME MATRIX MEANS OF FOURIER SERIES}

\author{
W. ŁENSKI AND B. SZAL
}

Abstract. The results corresponding to some theorems of S. Lal [Appl. Math. and Comput. 209 (2009), 346-350] and the results of the authors [Banach Center Publ., 95, (2011), 339-351] are shown. The same and sometimes better degrees of pointwise approximation as in mentioned papers by weaker assumptions on considered functions and examined summability methods are obtained. From presented pointwise results the estimation on norm approximation are derived. Some special cases as corollaries for iteration of the Nörlund or the Riesz method with the Euler one are also formulated.

Mathematics subject classification (2010): 42A24.

Keywords and phrases: Degree of approximation, Fourier series.

\section{REFERENCES}

[1] S. LAL, Approximation of functions belonging to the generalized Lipschitz Class by $C_{1} N p$ summability method of Fourier series, Appl. Math. and Comput., 209 (2009) 346-350.

[2] L. LeINDLER, Integrability conditions pertaining to Orlicz space, J. Inequal. Pure and Appl. Math., 8 (2) (2007), Art. 38, 6 pp.

[3] W. ŁENSKI AND B. SZAL, Approximation of functions from $L^{p}(\omega)_{\beta}$ by general linear operators of their Fourier series, Banach Center Publ. 95, (2011), 339-351.

[4] W. EENSKI AND B. SZAL, Approximation of functions from $L^{p}(\tilde{w})_{\beta}$ by linear operators of conjugate Fourier series, Banach Center Publ. 92 (2011), 237-247.

[5] W. EENSKI AND B. SZAL, On pointwise approximation of conjugate functions by some Hump matrix means of conjugate fourier series, Journal of Function Spaces, Volume 2015 (2015), Article ID470205.

[6] H. K. Nigam and A. Sharma, On $(N, p, q)(E, 1)$ Summability of Fourier Series, Internat. J. Math. Math. Sci., Volume 2009, Article ID 989865, 8 pages.

[7] H. K. Nigam And K. Sharma, Degree of approximation of a class of functions by $(C, 1)(E, q)$ means of Fourier series, Int. J. Appl. Math. 41:2, IJAM-41-2-07 (2011).

[8] A. Zygmund, Trigonometric series, Cambridge, 2002. 